\title{
Characterization of Dispersion and Ultrafine-particle Emission Factors Based on Near-roadway Monitoring Part II: Heavy Duty Vehicles
}

\author{
Sheng Xiang, Yu Ting Yu, Zhice Hu, Kenneth E. Noll* \\ Department of Civil, Architecture and Environmental Engineering, Illinois Institute of Technology, Chicago, IL 60616, \\ USA
}

\begin{abstract}
This paper presents a comprehensive set of ultrafine particles (UFPs) emission factors (EFs) for heavy duty vehicles (HDVs) as a function of vehicle flow rate, speed, and mode of operation (free flow and congestion) using 664 measurements of UFPs, carbon dioxide $\left(\mathrm{CO}_{2}\right)$, meteorology and traffic conditions near a major roadway (average daily traffic 300,000 day ${ }^{-1}$ ). 5-min samples were collected for 2 to 3 hour time period on 60 days between 2015 and 2018. The average traffic-induced concentration of UFPs was $11,300 \mathrm{pt} \mathrm{cm}^{-3}$ for free flow and $12,400 \mathrm{pt} \mathrm{cm}^{-3}$ for congestion. Results demonstrate that HDVs produce significantly more dispersion (30x) than light duty vehicles (LDVs). The additional dispersion from HDVs results in the minimum pollutant concentrations occurring at the highest vehicle flow rate. EFs for UFPs are determined using inverse modeling based on the calculated $\mathrm{CO}_{2}$ dispersion. This eliminates the need to rely on air-quality models to estimate dispersion. The EFs for HDVs range from $4 \times 10^{14}$ to $20 \times 10^{14}\left(\mathrm{pt} \mathrm{km}^{-1} \mathrm{veh}^{-1}\right)$. The variations in EFs are correlated with variations in vehicle flow rate and speed. The average UFP EFs for HDVs are significantly higher (3x) for congestion compared to free flow. UFP EFs for HDVs are more sensitive to speed in congestion compare to in free flow conditions. Thus, even a moderate increase in HDVs speed or mitigation of congestion will have a significant impact on lowering UFP concentrations.
\end{abstract}

Keywords: Air quality monitoring; Ultrafine particle; Dispersion; Heavy-duty vehicle emission; Free flow and congestion.

\section{INTRODUCTION}

Vehicle emission factors (EFs) that account for vehicle flow rate and type (light duty and heavy duty) and vehicle mode of operation (free flow and congestion) are needed to model vehicle emissions and provide insight into human exposure. This is due to the fact that heavy duty vehicles (HDVs) are usually under $5 \%$ of the total vehicle flow rate on highways but contribute more than half of the ultrafine particle (UFP) emissions (Abu-Allaban et al., 2002; Ntziachristos et al., 2007; Xiang et al., 2018). This makes the determination of EFs for HDVs very important. However, in order to estimate the real-world EFs, the dispersion process near roadways needs to be characterized. Researchers have determined that turbulent mixing is a dominate mechanism for UFP dispersion (Zhang and Wexler, 2002, 2004; Zhang et al., 2004). Thus, understanding the dynamic of dispersion is critical. However, there is no generally applicable method to directly relate dispersion to turbulence near roadways. Even though the

\footnotetext{
${ }^{*}$ Corresponding author.

Tel.: 312.545.8343; Fax: 312.567.8874

E-mail address: noll@iit.edu
}

enhancement in turbulence caused by HDVs has been studied widely, more research is needed that relates dispersion from HDV to turbulence from HDV.

The turbulence generated by vehicle motion is called vehicle-induced turbulence (VIT). VIT produces the dispersion of vehicle exhaust emissions in the near roadway environment and is related to mechanically induced circulations associated with the so-called "wake" behind vehicles. The region of flow immediately behind the vehicle is called the "wake". The wake is a complicated region of flow separations associated with moving vehicles that generate random, three-dimensional, flow fluctuations (turbulence).

VIT has been evaluated using wind tunnels, computational fluid dynamic models (CFD) and field measurements. Wind tunnel studies (Eskridge and Thompson, 1982; Pavageau and Schatzmann, 1999; Kastner-Klein et al., 2000; Carpentieri et al., 2012; McArthur et al., 2016; Lo and Kontis, 2017) have demonstrated that the extent of the wake depends on the height of the vehicle, the aspect ratio (length/height), type of vehicle and the vehicle mode of operation (free flow and congestion). The largest wake behind light duty vehicles (LDVs) extends to about 15 times the vehicle height (Eskridge and Hunt, 1979; Eskridge and Thompson, 1982) and HDVs produce significantly larger wakes than LDVs (McArthur et al., 2016; Lo and Kontis, 2017; Miller et al., 2019). The 
results from these studies indicate that variation in VIT cannot be neglected when evaluating dispersion in near roadway environments.

VIT has also been studied using CFD models that simulate dispersion near roadways as well as vehicle flow patterns to estimate pollutant concentrations (Sahlodin et al., 2007; Wang et al., 2009; Wang and Zhang, 2012; Wang et al., 2013; Huang et al., 2014; Bhautmage and Gokhale, 2016; Kim et al., 2016). These results were then compared to measured concentrations to evaluate modeled turbulence and dispersion. In computational models, dispersion is usually considered to be an empirical property of the turbulent flow. Results from CFD studies indicate that by assuming VIT is uniform within the wake structure, the VIT from vehicle movements can eventually reach a steady-state where the continuity of the vehicle flow prevents the turbulence from decaying. Under these conditions, the flow rate of the vehicles is large enough to produce a continuous, steady-state flow where the VIT does not increase with an increase in vehicle flow rate. When vehicle flow rate is low, the VIT is not continuous and increases with vehicle flow rate. This represents unsteadystate flow.

Field experiments have been conducted to assess VIT near roadways from vehicles (Trivikrama Rao et al., 1979; Chock, 1980; Rao et al., 2002; Kalthoff et al., 2005; AlonsoEstébanez et al., 2012; Gordon et al., 2012; Tong et al., 2015; Miller et al., 2019). These field studies indicate that there is a significant increase in turbulence near roadways due to vehicle movements on roadways and VIT can be affected by vehicle type, flow rate and mode of operation.

In this study, near roadway dispersion was estimated based on modeled $\mathrm{CO}_{2}$ EFs and measured vehicle flow rate and $\mathrm{CO}_{2}$ concentrations. 664 samples were collected at 5-min interval on a total of 60 days for a 2 to 3 hour sampling period between 2015 and 2018. $\mathrm{CO}_{2}$ emission factors (EFs) were calculated from MOVES for different vehicle type, flow rate and mode of operation (free flow and congestion) and combined with $\mathrm{CO}_{2}$ and traffic measurements to calculate real-world dispersion near a roadway from LDVs and HDVs. Variations in dispersion of $\mathrm{CO}_{2}$ were determined as a function of vehicle flow rate and vehicle mode of operation. Since the vehicle fleet is usually a mixture of LDVs and HDVs, it is difficult to accurately separate the UFP contribution due to LDVs and HDVs. To address this issue, UFP EFs of LDVs were determined based on a previous study at an LDV-only roadway (Xiang et al., 2019, this issue) and used to calculate EFs from HDVs.

\section{METHODS}

\section{Monitoring Site}

Field measurements were conducted near the Dan Ryan Expressway (DRE) in Chicago, IL a few kilometers south of the city center (see Fig. 1) and next to the Illinois Institute of Technology campus. Information from the Illinois Department of Transportation (IDOT, 2016) provided the annual average daily traffic flow rate of 300,000 veh day ${ }^{-1}$ with $8.4 \%$ HDVs. The sampling program was conducted during the summer and fall from 2015 to 2018 (total of 664 5-min measurements). Each 5-min was a separate sampling period. The freeway is depressed 6 meters and located between a parking lot and low-rise buildings. The freeway has 14 lanes, separated into north and south bound roadways by a $10-\mathrm{m}$ wide subway platform. For each direction, four express lanes are restricted to LDVs and three local lanes are open to both LDVs and HDVs. $\mathrm{CO}_{2}$, UFP and meteorology

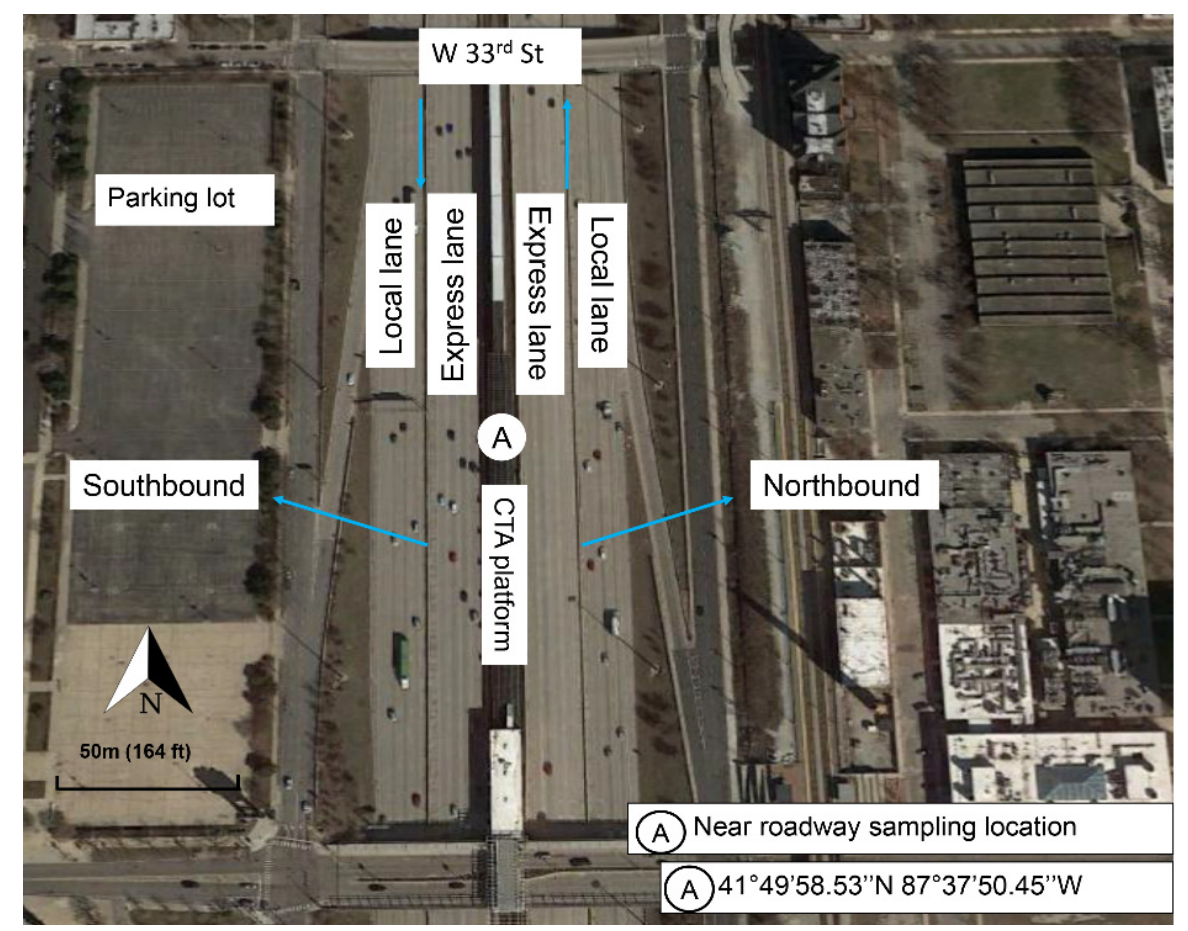

Fig. 1. Map of sampling area near Dan Ryan Expressway with the near roadway sampling site (A) and cross-section. 
measurements were collected with handheld, fast-response instruments simultaneously at a near roadway and a background location. Near roadway sampling was conducted on the east side of the subway platform (site A) 3 meters from the edge of the roadway at an elevation of 4 meters when there were easterly winds. Background measurements were recorded upwind, more than $200 \mathrm{~m}$ away from the roadway (not shown). The traffic information was recorded on an overpass ( $33^{\text {rd }}$ street) that allows all lanes of traffic to be (flow rate and speed) recorded. The determination of vehicle types was made manually, LDVs were defined as passenger cars and trucks while HDVs were defined as long combination haul with either 10 or 18 wheeled (Gordon et al., 2012). Since site A was in the middle of DRE, only oneside traffic (northbound) were used to evaluate near roadway measurements. Details concerning the sampling program are reported elsewhere (Xiang et al., 2018). Sampling was conducted only when easterly winds occurred, and wind direction was within $45^{\circ}$ of normal to the roadway. Only data with all lanes free flow or all lanes congestion was used for data analysis.

\section{Estimation of near Roadway Dispersion}

The near roadway dispersion was calculated based on theoretical relationships between vehicle emissions, meteorology and pollutant concentrations (Palmgren et al., 1999). To characterize near roadway dispersion, a tracer gas with a well-known emission factor (EF) is needed (Imhof et al., 2005; Zhang et al., 2005; Jones and Harrison, 2006; Wang et al., 2010; Nickel et al., 2013). In this study, $\mathrm{CO}_{2}$ was chosen as the tracer gas. The reason that $\mathrm{CO}_{2}$ is an ideal tracer gas was demonstrated in a previous study (Xiang et al., 2019, this issue). Near roadway fleet dispersion can be estimated with EFs of $\mathrm{CO}_{2}$, vehicle flow rates and $\mathrm{CO}_{2}$ concentration as shown in Eq. (1).

$$
D_{\text {fleet }}=\frac{E F_{C O 2, L D V} \times N_{L D V}+E F_{C O 2, H D V} \times N_{H D V}}{C_{C O 2}-C_{C O 2, B G}}
$$

In Eq. (1), $D_{\text {fleet }}$ is near roadway fleet dispersion $\left(\mathrm{m}^{2} \mathrm{~s}^{-1}\right)$. $\mathrm{EF}_{\mathrm{CO} 2 \mathrm{LDV}}$ and $\mathrm{EF}_{\mathrm{CO} 2, \mathrm{HDV}}$ are emission factor of $\mathrm{CO}_{2}\left(\mathrm{~g} \mathrm{~m}^{-1} \mathrm{veh}^{-1}\right)$ modeled by MOVES for LDVs and HDVs, respectively. $\mathrm{N}_{\mathrm{LDV}}$ and $\mathrm{N}_{\mathrm{HDV}}$ are the vehicle flow rate of the LDVs and HDVs, respectively $\left(\mathrm{veh} \mathrm{s}^{-1}\right)$. The differences between near roadway concentrations $\left(\mathrm{C}_{\mathrm{CO} 2}\right)$ and background concentrations $\left(\mathrm{C}_{\mathrm{CO} 2, \mathrm{BG}}\right)$ provides the $\mathrm{CO}_{2}$ concentrations contributed by vehicle emissions $\left(\mathrm{g} \mathrm{m}^{-3}\right)$. The 5-min near roadway measurements are subdivided into (1) all lanes free flow and all lanes congestion conditions, (2) uniform fleet vehicle flow rate intervals of $1,000 \mathrm{veh}^{-1}$. Categorizing the near roadway fleet dispersion by vehicle flow rate and mode of operation allows the estimation of the vehicle fleet EFs as a function of vehicle flow rate, speed, mode of operation and type of vehicle (HDVs and LDVs). In this study, for each vehicle type (LDVs and HDVs) and mode of operation (free flow and congestion), $D_{\text {fleet }}$ is assumed to occur in the vehicle wake and considered as a combination of dispersion from both LDVs and HDVs $\left(\mathrm{D}_{\text {fleet }}=\mathrm{D}_{\mathrm{LDV}}+\mathrm{D}_{\mathrm{HDV}}\right)$. This linear relationship was suggested by other researchers and assume no interaction between wakes from different vehicle (Benson, 1984; Grønskei, 1988; Berkowicz et al., 1997).

The ensemble means are calculated for each vehicle flow intervals $\left(1,000 \mathrm{veh} \mathrm{h}^{-1}\right)$ and used to evaluate dispersion. The use of ensemble means allow changes in measured pollutant concentrations due to variations in vehicle flow rate and dispersion to be evaluated. (Arya, 1999; Seinfeld and Pandis, 2016).

\section{Determination of UFP EFs for Traffic Fleet}

Since the $\mathrm{CO}_{2}$ and particles are homogeneously mixed (Kurniawan and Schmidt-Ott, 2006; Ntziachristos et al., 2007; Rönkkö et al., 2017; Hietikko et al., 2018), UFP emission factors (EFs) can be estimated using $\mathrm{D}_{\text {fleet }}$, measured UFP concentrations and vehicle flow rates (See Eq. (2)). This approach eliminates the need to rely on a dispersion model to determine the near roadway dispersion.

$$
E F_{U F P, f l e e t}=\frac{\left(C_{U F P}-C_{U F P, B G}\right) \times D_{\text {fleet }}}{N_{\text {fleet }}}
$$

In Eq. (2), EF UFP,fleet is the vehicle fleet UFP emission factor $\left(\mathrm{pt} \mathrm{m}^{-1} \mathrm{veh}^{-1}\right)$. $\mathrm{C}_{\mathrm{UFP}}$ and $\mathrm{C}_{\mathrm{UFP}, \mathrm{BG}}$ are UFP concentrations measured at near roadway and background locations, respectively $\left(\mathrm{pt} \mathrm{m}^{-3}\right)$. Differences between $\mathrm{C}_{\mathrm{UFP}}$ and $\mathrm{C}_{\mathrm{UFP}, \mathrm{BG}}$ are considered as UFP contributed by vehicles. $\mathrm{N}_{\text {fleet }}$ is total vehicle flow rate $\left(\mathrm{veh} \mathrm{s}^{-1}\right)$, that is the sum of the number of LDVs and HDVs $\left(\mathrm{N}_{\text {fleet }}=\mathrm{N}_{\mathrm{LDV}}+\mathrm{N}_{\mathrm{HDV}}\right)$. Because UFP and $\mathrm{CO}_{2}$ were simultaneously measured, total vehicle flow rate $\left(\mathrm{N}_{\text {fleet }}\right)$ and near roadway fleet dispersion $\left(\mathrm{D}_{\text {fleet }}\right)$ from Eq. (1) can be used in Eq. (2).

One of the critical problems when analyzing roadway data is that the vehicle fleet consists of both LDVs and HDVs. To differentiate the EFs for different vehicle types (LDVs and HDVs), a mass balance equation, Eq. (3) can be applied. A similar equation has been used by other researchers (Palmgren et al., 1999; Imhof et al., 2005; Morawska et al., 2005; Zhang et al., 2005; Wang et al., 2010; Nickel et al., 2013; Krecl et al., 2018). LDV EFs determined for Lake Shore Drive (LSD) are available as input to solve Eq. (3) for EFs for HDVs (Xiang et al., 2019).

$$
\mathrm{EF}_{\mathrm{UFP}, \text { fleet }} \times \mathrm{N}_{\text {fleet }}=\mathrm{EF}_{\mathrm{UFP}, \mathrm{LDV}} \times \mathrm{N}_{\mathrm{LDV}}+\mathrm{EF}_{\mathrm{UFP}, \mathrm{LDV}} \times \mathrm{N}_{\mathrm{HDV}}
$$

In Eq. (3), EF UFP,LDV and EF UFP,HDV are the UFP emission factor for LDV and HDV, respectively $\left(\mathrm{pt} \mathrm{m}^{-1} \mathrm{veh}^{-1}\right) . \mathrm{N}_{\mathrm{LDV}}$ and $\mathrm{N}_{\mathrm{HDV}}$ are the vehicle flow rate for LDVs and HDVs, respectively (veh s${ }^{-1}$ ). Eq. (3) was used for each data interval. By solving Eq. (3), UFP EFs for HDVs can be estimated as a function of HDV flow rates and vehicle mode of operation.

\section{RESULTS AND DISCUSSION}

\section{Overview of Meteorological Condition}

In this study, the average temperature was $22( \pm 3)^{\circ} \mathrm{C}$ for free flow and $21( \pm 4)^{\circ} \mathrm{C}$ for congestion; the average relative 
humidity was $53( \pm 12) \%$ for free flow and $60( \pm 12) \%$ for congestion. Atmospheric stability class were neutral or stable (class D) for most of the sampling days. On the average, free flow had higher wind speeds $\left(2.0 \pm 0.7 \mathrm{~m} \mathrm{~s}^{-1}\right)$ than congestion $\left(1.5 \pm 0.4 \mathrm{~m} \mathrm{~s}^{-1}\right)$.

\section{Vehicle Flow Rate and Speed}

Fig. 2 provides information on the vehicle speed-flow relationship during the sampling program and is typical of traffic conditions on many roadways (Mannering, 2013). The figure indicates that there were significant variations in vehicle driving conditions that can be related to vehicle EFs. The figure indicates that vehicle flow rate is at a maximum capacity at a speed near $70 \mathrm{~km} \mathrm{~h}^{-1}$ for LDVs and $55 \mathrm{~km} \mathrm{~h}^{-1}$ for HDVs and decreases for higher and lower speeds. The driving condition is considered free flow on the upper part of the speed-flow curves which represents conditions when the vehicles are unhindered by other vehicles. Under this driving condition, as the vehicle flow rate increases the distance between individual vehicles decreases and results in a reduction of the vehicle speed. The average speed of LDVs for free flow conditions was $110 \mathrm{~km} \mathrm{~h}^{-1}$ and $28 \mathrm{~km} \mathrm{~h}^{-1}$ for congestion. For free flow conditions, HDV speed ranged from 60 to $110 \mathrm{~km} \mathrm{~h}^{-1}$ with an average near $90 \mathrm{~km} \mathrm{~h}^{-1}$. For congestion, the average speed for HDV was $26 \mathrm{~km} \mathrm{~h}^{-1}$ with a range from 9 to $50 \mathrm{~km} \mathrm{~h}^{-1}$. The express lanes generally had a higher speed than the local lanes and HDVs generally had a lower speed than LDVs. The large variations in speed and flow for vehicles indicated that there was significant variation in traffic conditions. These variations were able to be observed due to the short sampling time (5-min). For each 5 -min sample, total vehicle flow rate $\left(\mathrm{N}_{\text {fleet }}\right)$ is equal to sum of LDV in express and local lanes $\left(\mathrm{N}_{L D V}\right)$ and HDV in local lanes $\left(\mathrm{N}_{H D V}\right)$. The range of the total vehicle flow rate is between 5,000 and 10,000 veh $\mathrm{h}^{-1}$.

\section{Determination of $\mathrm{CO}_{2} \mathrm{EF}$ for $\mathrm{LDVS}$ and $\mathrm{HDVS}$}

Fig. 3 presents the $\mathrm{CO}_{2}$ EFs for LDVs and HDVs determined using MOVES as a function of vehicle flow rate under different traffic conditions (free flow and congestion). The LDV EFs were near $200 \mathrm{~g} \mathrm{~km}^{-1} \mathrm{veh}^{-1}$ and the HDV EFs were near $1,200 \mathrm{~g} \mathrm{~km}^{-1} \mathrm{veh}^{-1}$ for free flow conditions. For congestion conditions, both the LDV and HDV EFs increased significantly ( $75 \%$ for LDVs and $100 \%$ for HDVs) when the total vehicle flow rate decreased from 10,000 to $3,000 \mathrm{veh} \mathrm{h}^{-1}$. For the overall average, $\mathrm{HDV} \mathrm{CO}_{2} \mathrm{EFs}$ are 6 times higher than LDVs for free flow and congestion conditions. The trend of $\mathrm{CO}_{2} \mathrm{EFs}$ in this study is in accordance with other studies. Liu and Frey (2015) reported that $\mathrm{LDV} \mathrm{CO}_{2} \mathrm{EFs}$ increased from 190 to $300 \mathrm{~g} \mathrm{~km}^{-1} \mathrm{veh}^{-1}$ as the speed decreased from 110 to $16 \mathrm{~km} \mathrm{~h}^{-1}$. Zhang et al. (2011) reported $\mathrm{HDV} \mathrm{CO}$ EFs varied from 1,030 to $1,700 \mathrm{~g} \mathrm{~km}^{-1} \mathrm{veh}^{-1}$ when speed decreased from 100 to $30 \mathrm{~km} \mathrm{~h}^{-1}$.

\section{$\mathrm{CO}_{2}$ and UFP Concentrations near Roadway}

Variations in the near roadway $\mathrm{CO}_{2}$ and UFP measured concentrations (background subtracted) as a function of total vehicle flow rate are shown in Fig. 4. The data for each HDV category were fitted by polynomial regression to represent the vehicle flow rate. For free flow and congestion conditions,

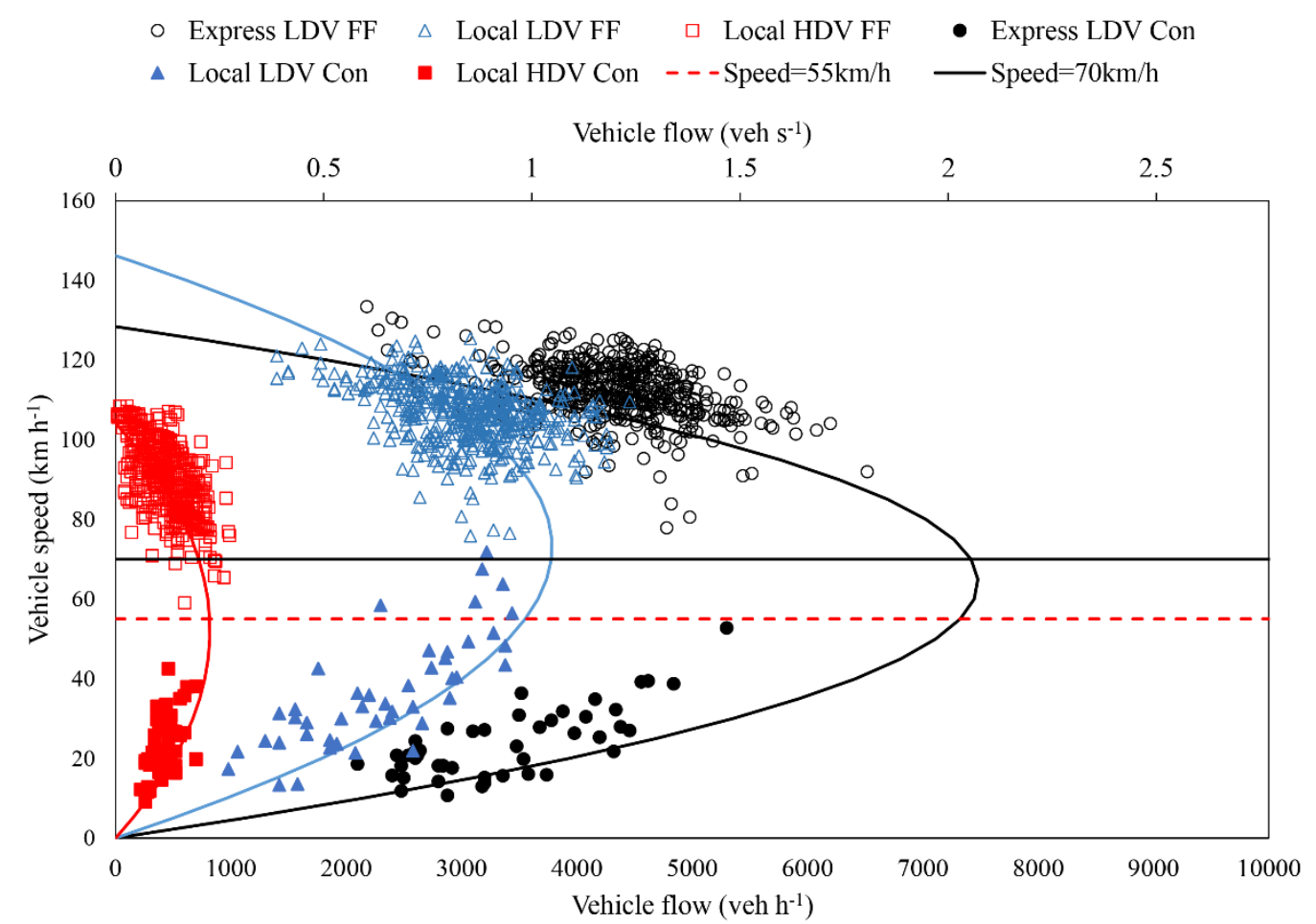

Fig. 2. Relationship between measured 5-min vehicle flow rate and speed near Dan Ryan Expressway under free flow (FF) and congestion (Con) condition. The 5-min traffic data were divided by lanes (local and expressway) and types of vehicle (heavy duty vehicle and light duty vehicle). 


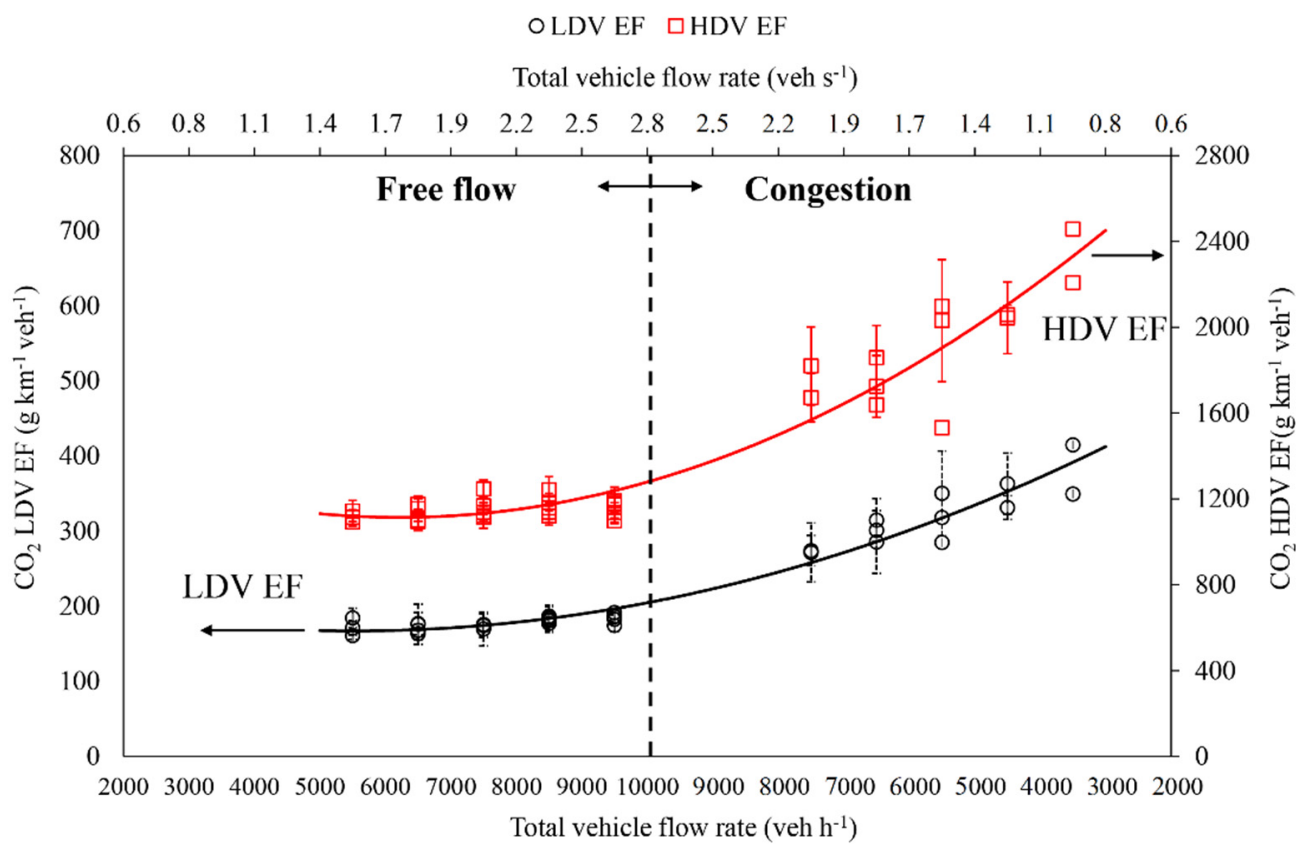

Fig. 3. Variations of average $\mathrm{CO}_{2}$ emission factors with total vehicle flow rate as a function of vehicle mode of operation for LDVs and HDVs. The 5-min data were first divided into 1,000 veh $\mathrm{h}^{-1}$ intervals then categorized into different HDV flow rates. Emission factors for each interval were modeled using MOVES, which requires traffic speed, temperature and relative humidity. MOVES default driving cycles and age distribution were used. Bars indicate one standard deviation.

concentrations of both $\mathrm{CO}_{2}$ and UFP decreased with an increase in fleet flow rate. The minimum concentration occurred at the highest vehicle flow rate. Application of Eq. (1) (next section) indicates that there is a significant increase in near roadway dispersion when there is an increase in the number of HDVs and this accounts for the decrease in concentrations at high flow rates. In a previous study near a LDV-only roadway (Xiang et al., 2019), concentrations of both $\mathrm{CO}_{2}$ and UFP increased when total vehicle flow rate increased (See Fig. 4(b)). These results indicate that HDVs have a significant impact on dispersion of pollutant concentrations near roadways because one would expect the concentration to increase with vehicle flow rate.

\section{Variation in Near Roadway Dispersion with Variation in HDV Flow Rate}

Eq. (1) was used to calculate near roadway fleet dispersion $\left(D_{\text {fleet }}\right)$ for each 1,000 veh $\mathrm{h}^{-1}$ interval. The calculations are based on the modeled $\mathrm{CO}_{2}$ EFs in Fig. 3 and the ensemble mean $\mathrm{CO}_{2}$ as a function of total vehicle flow rate and HDV flow rate from Fig. 4(a). Example calculations of dispersion as a function of vehicle flow rate and type are shown in Table 1. Table 1 indicates that the ratio of HDV/LDV dispersion varied between 25 and 40 depending on traffic conditions (HDV flow rate and speed). On the average, near roadway dispersion from one $\mathrm{HDV}$ is, nearly 30 times higher than one LDV. Even when the vehicle fleet flow rate was similar $\left(9,000\right.$ to $\left.10,000 \mathrm{veh} \mathrm{h}^{-1}\right)$, increasd HDV flow rate resulted in an increase in $D_{\text {fleet. }}$ This is because of the differences in the ratio of HDV/LDV dispersion.

Fig. 5 presents the variations of $\mathrm{D}_{\text {fleet }}$ as a function of total flow rate for different HDV flow rates near DRE. Polynomial least-square regression was used to fit the data. $\mathrm{D}_{\text {fleet }}$ increased when both the total vehicle flow rate and the HDV flow rate increased for free flow and congestion conditions. However, the largest increases are associated with increases in HDV flow rate. $D_{\text {fleet }}$ increased nearly 3 times $\left(6-18 \mathrm{~m}^{2} \mathrm{~s}^{-1}\right)$ at a fleet flow rate of $10,000 \mathrm{veh} \mathrm{h}^{-1}$ when the HDV flow rate increased from 0 to $1,000 \mathrm{veh} \mathrm{h}^{-1}$. When the information in Figs. 2 and 5 are combined, one can see that $D_{\text {fleet }}$ varies with both vehicle speed and vehicle flow rate. Compared to the study conducted near a LDV-only roadway (Xiang et al., 2019), one unit of increase in vehicle fleet flow rate $\left(1,000 \mathrm{veh} \mathrm{h}^{-1}\right)$ in DRE produce more $\mathrm{D}_{\text {fleet }}$ depending on the HDV flow rate in vehicle fleet. This is due to the fact that one HDV can produce more dispersion than one LDV, as indicated in Table 1.

\section{Determination of UFP EFs for Traffic Fleet}

Fig. 6 provides the calculated fleet UFP EFs as a function of total vehicle flow rate, HDV flow rate, and vehicle mode of operation using Eq. (2). The vehicle fleet EFs for free flow conditions decreased when total vehicle flow rate increased from 5,000 to $10,000 \mathrm{veh} \mathrm{h}^{-1}$ with an average value of 0.52 $\times 10^{14}\left( \pm 0.17 \times 10^{14}\right) \mathrm{pt} \mathrm{km}^{-1} \mathrm{veh}^{-1}$. However, the vehicle fleet EFs increased by 4 times when the HDV flow rate increased from 0-200 to 800-1000 veh $\mathrm{h}^{-1}$. For congestion conditions, average fleet EFs were $0.87 \times 10^{14}\left( \pm 0.18 \times 10^{14}\right)$

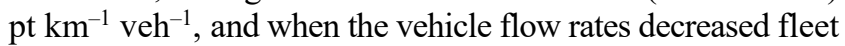
EFs increased rapidly (total increase is 6 times). These results can be compared to UFP EFs for LDVs that increased by $20 \%$ (from $0.1 \times 10^{14}$ to $0.12 \times 10^{14} \mathrm{pt} \mathrm{km}^{-1} \mathrm{veh}^{-1}$ ) with LDV flow rate from 5,000 to $10,000 \mathrm{veh} \mathrm{h}^{-1}$ (Xiang et al., 2019). 
(a)

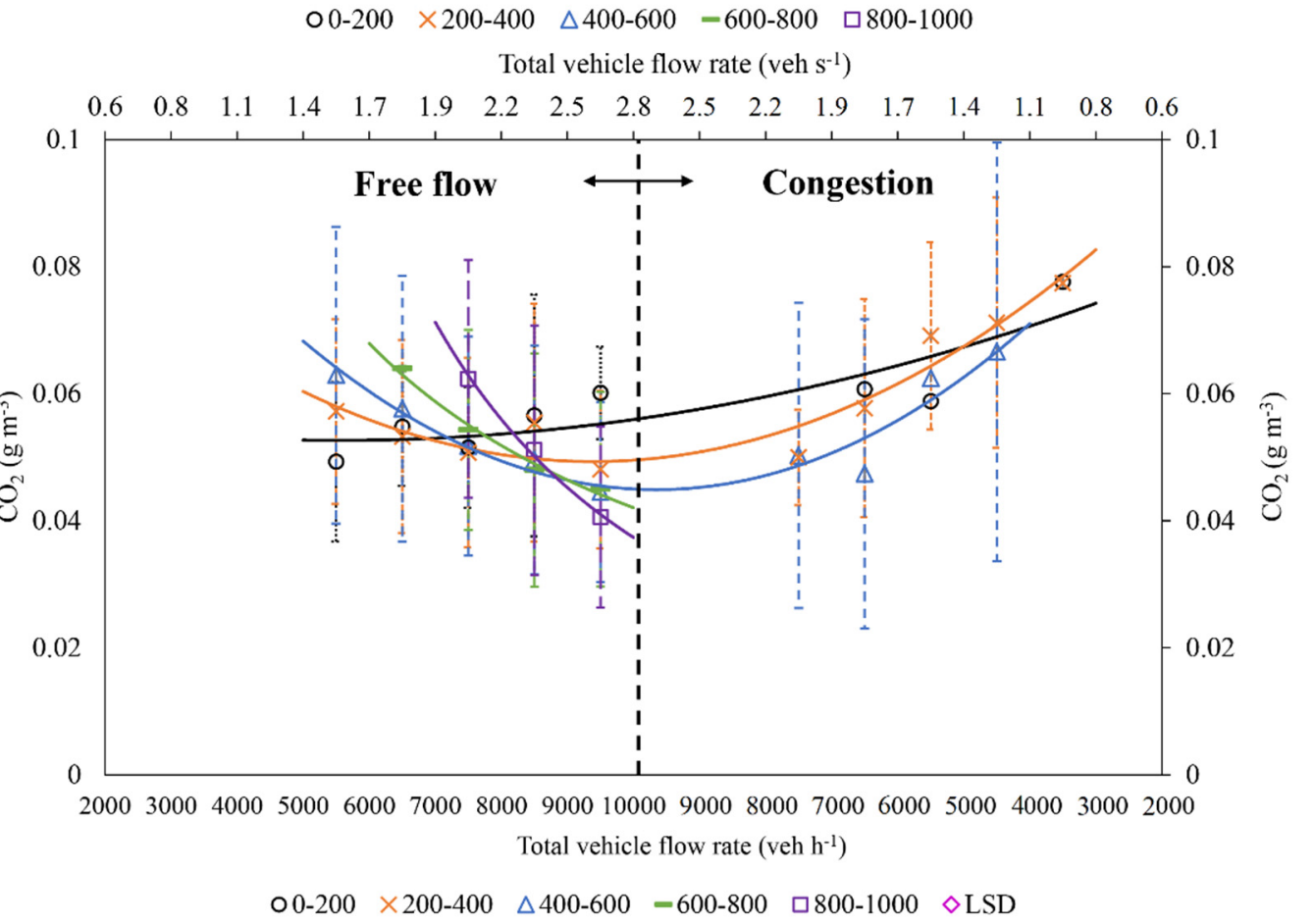

(b)

Total vehicle flow rate $\left(\right.$ veh s$\left.^{-1}\right)$

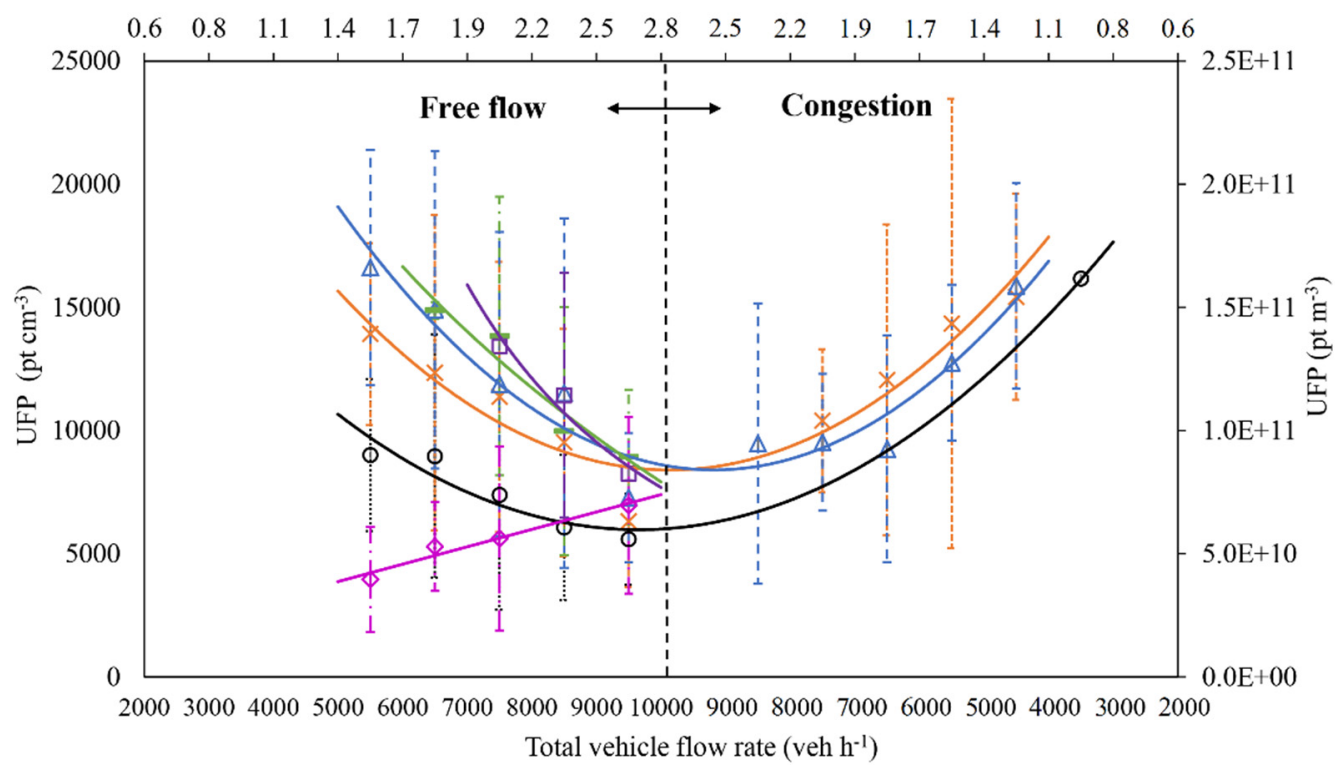

Fig. 4 Ensemble means of 5-min measured (a) $\mathrm{CO}_{2}$ concentration and (b) UFP concentration (both are background subtracted) variations with total vehicle flow rate for free flow and congestion near DRE. The 5-min data were first divided into $1,000 \mathrm{veh}^{-1}$ intervals then categorized into different HDV flow rates. LSD data for UFP concentrations were modified from Xiang et al. (2019). Bars indicate one standard deviation.

\section{Determination of UFP EFs for HDVS}

Fig. 7 provides the estimated HDV UFP EFs as a function of HDV flow rate, speed, and mode of operation using Eq. (3). HDV EFs were calculated based on total vehicle fleet EFs in Fig. 6 and the LDV EFs provided from a previous study (Xiang et al., 2019). HDV EFs were $6.6 \times 10^{14}( \pm 1.2$ $\left.\times 10^{14}\right) \mathrm{pt} \mathrm{km}^{-1} \mathrm{veh}^{-1}$ for free flow and were 2 times higher for congestion condition $\left(16 \pm 3.7 \times 10^{14} \mathrm{pt} \mathrm{km}^{-1} \mathrm{veh}^{-1}\right)$. To better understand the dynamic of HDV UFP EFs as a function of vehicle mode of operation, Fig. 7 also presents HDV UFP EFs as a function of HDV speed. As the HDV speed decreased from 100 to $10 \mathrm{~km} \mathrm{~h}^{-1}$, HDV UFP EFs increased 3 times.

\section{CONCLUSIONS and DISCUSSION}

Variations of near roadway fleet dispersion $\left(\mathrm{D}_{\text {fleet }}\right)$ were calculated using 5-min $\mathrm{CO}_{2}$ measurements, vehicle flow rate 
Table 1. Example calculations using Eq. (1) for 9,000 veh $\mathrm{h}^{-1} \leq$ total flow rate $<10,000 \mathrm{veh} \mathrm{h}^{-1}$ data interval under free flow condition near DRE and LSD.

\begin{tabular}{|c|c|c|c|c|c|c|c|c|c|c|c|}
\hline Roadway & Date & $\begin{array}{l}\text { HDV flow } \\
\text { rate }\left(\text { veh h}^{-1}\right)\end{array}$ & $\begin{array}{l}\text { LDV flow } \\
\text { rate }\left(\text { veh }^{-1}\right)\end{array}$ & $\begin{array}{l}\mathrm{CO}_{2} \text { fleet } \mathrm{EF} \\
\left(\mathrm{g} \mathrm{m}^{-1} \text { veh }^{-1}\right)\end{array}$ & $\begin{array}{l}\mathrm{CO}_{2} \\
\left(\mathrm{~g} \mathrm{~m}^{-3}\right)\end{array}$ & $\begin{array}{l}D_{\text {fleet }} \\
\left(\mathrm{m}^{2} \mathrm{~s}^{-1}\right)\end{array}$ & $\begin{array}{l}D_{L D V}^{\#} \\
\left(m^{2} \mathrm{~s}^{-1}\right)\end{array}$ & $\begin{array}{l}\mathrm{D}_{\mathrm{HDV}} \mathrm{s} \\
\left(\mathrm{m}^{2} \mathrm{~s}^{-1}\right)\end{array}$ & $\begin{array}{l}\text { LDV } \\
\text { normalized } \\
\text { dispersion }\end{array}$ & $\begin{array}{l}\text { HDV } \\
\text { Normalized } \\
\text { dispersion }^{\&}\end{array}$ & $\begin{array}{l}\text { Ratio of } \\
\text { HDV/LDV } \\
\text { dispersion* }\end{array}$ \\
\hline LSD & $9 / 20 / 2016$ & 0 & 9960 & 0.19 & 0.109 & 4.8 & 4.8 & 0 & 1.7 & n.a. & n.a. \\
\hline DRE & 9/16/2018 & 160 & 9020 & 0.18 & 0.060 & 7.7 & 4.8 & 2.9 & 1.9 & 65.3 & 34.4 \\
\hline DRE & $6 / 18 / 2016$ & 360 & 8940 & 0.21 & 0.048 & 11.3 & 4.7 & 6.6 & 1.9 & 66.0 & 34.7 \\
\hline DRE & $3 / 29 / 2016$ & 450 & 9090 & 0.23 & 0.045 & 13.5 & 4.8 & 8.7 & 1.9 & 69.6 & 36.6 \\
\hline DRE & $7 / 27 / 2016$ & 660 & 8420 & 0.27 & 0.045 & 15.1 & 4.7 & 10.4 & 2.0 & 56.7 & 28.4 \\
\hline DRE & $8 / 12 / 2015$ & 960 & 8460 & 0.29 & 0.041 & 18.5 & 4.7 & 13.8 & 2.0 & 51.8 & 25.9 \\
\hline
\end{tabular}

${ }^{\#} \mathrm{D}_{\mathrm{LDV}}$ is calculated using the best fit line for LSD data from previous study (Xiang et al., 2019).

${ }^{\$} \mathrm{D}_{\mathrm{HDV}}$ is calculated using $\mathrm{D}_{\mathrm{LDV}}$ from LSD, where $\mathrm{D}_{\mathrm{HDV}}=\mathrm{D}_{\text {fleet }}-\mathrm{D}_{\mathrm{LDV}}$.

${ }^{\wedge}$ LDV normalized dispersion is defined as near roadway LDV dispersion ( $\left.\mathrm{D}_{\mathrm{LDV}}\right)$ divided by LDV flow rate $\left(\mathrm{N}_{\mathrm{LDV}}\right)$.

${ }^{\&} \mathrm{HDV}$ normalized dispersion is defined as near roadway HDV dispersion $\left(\mathrm{D}_{\mathrm{HDV}}\right)$ divided by HDV flow rate $\left(\mathrm{N}_{\mathrm{HDV}}\right)$.

* Ratio of HDV/LDV dispersion is the ratio of HDV normalized dispersion to LDV normalized dispersion.

O $0-200 \times 200-400 \quad \Delta 400-600-600-800 \quad \square 800-1000 \diamond$ LSD

Total vehicle flow rate $\left(\right.$ veh $\left.^{-1}\right)$

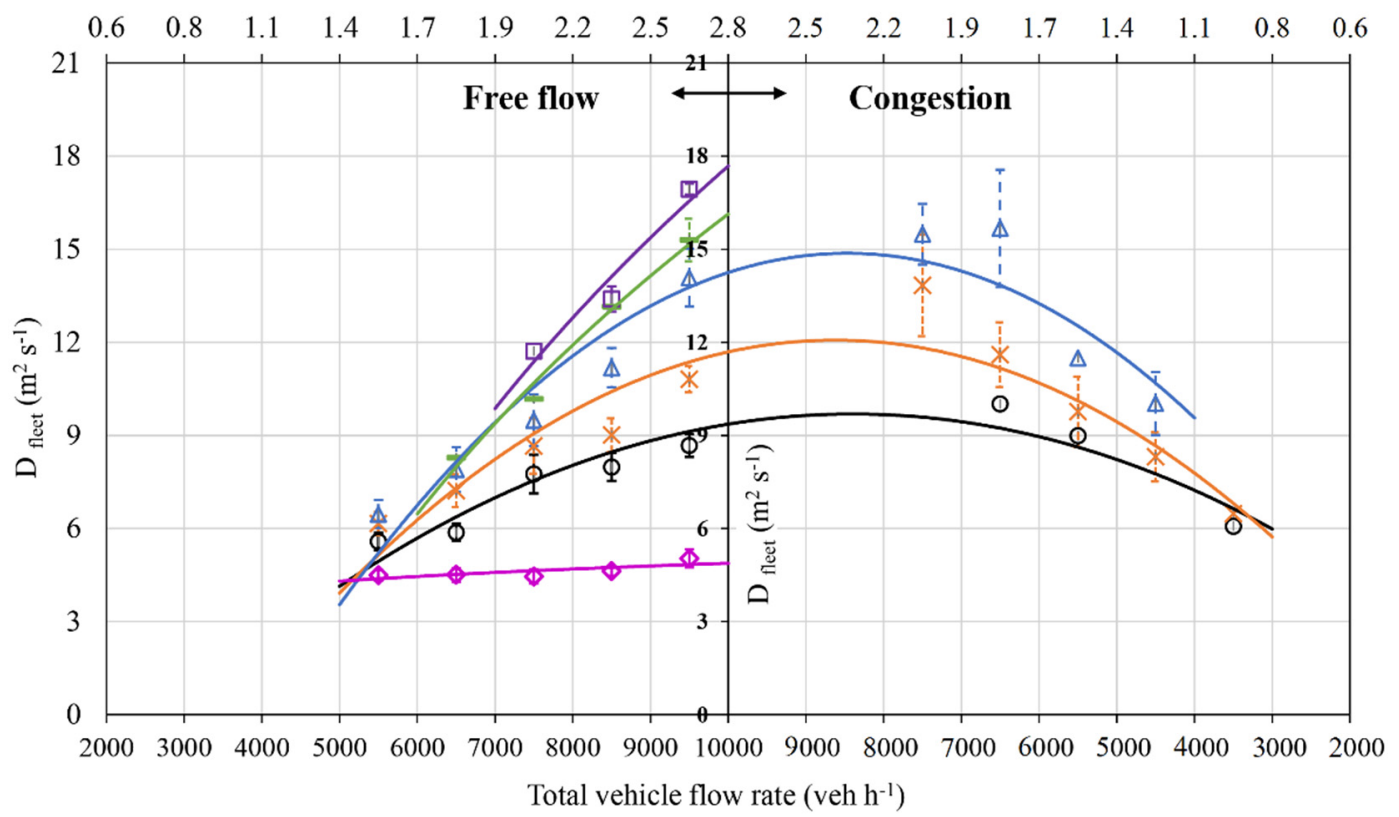

Fig. 5. Variations of near roadway fleet dispersion $\left(\mathrm{D}_{\text {fleet }}\right)$ with HDV flow rate and vehicle mode of operation determined with Eq (1). The data were first divided into 1,000 veh $\mathrm{h}^{-1}$ intervals then categorized into different HDV flow rates (See Table 1). LSD data is modified from Xiang et al., 2019. Bars indicate one standard deviation.

and a vehicle emission model (MOVES). Results indicate that HDVs not only generate significantly more UFP emissions than LDVs they also produce significantly more dispersion. The average ratio of HDV to LDV dispersion from individual vehicles was near 30 for free flow conditions. Based on Eq. (1) and Fig. 5, the near roadway fleet dispersion increased when the flow rate of HDVs increased under both free flow and congestion conditions. One of the important conclusions of this study is that the enhancement of dispersion due to HDVs leads to enhanced dispersion for both LDVs and HDVs emissions. This resulted in the lowest UFP and $\mathrm{CO}_{2}$ pollutant concentrations occurring during the highest vehicle flow rates. Identifying the near roadway dispersion from HDVs is critical because the HDVs provide the dispersion of emissions from both HDVs and LDVs.

This study also provides a comprehensive set of UFP emission factors (EFs) for HDVs as a function of vehicle flow rate, speed, and mode of operation. The average ratio of HDV to LDV UFP EFs was 44 for free flow and 125 for congestion. The emissions from individual HDVs were 3 times higher during congestion than free flow conditions. HDVs EFs ranged from $10^{14}$ to $10^{15} \mathrm{pt} \mathrm{km}^{-1} \mathrm{veh}^{-1}$ and LDVs

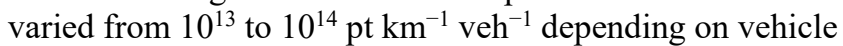
flow rate and mode of operation. Results from other studies are presented in Table 2 (Imhof et al., 2005; Morawska et al., 2005; Birmili et al., 2009; Wang et al., 2010; Nickel et al., 2013; Krecl et al., 2017; Krecl et al., 2018). For free flow condition (HDV speed $>55 \mathrm{~km} \mathrm{~h}^{-1}$ ), EFs ranged from 


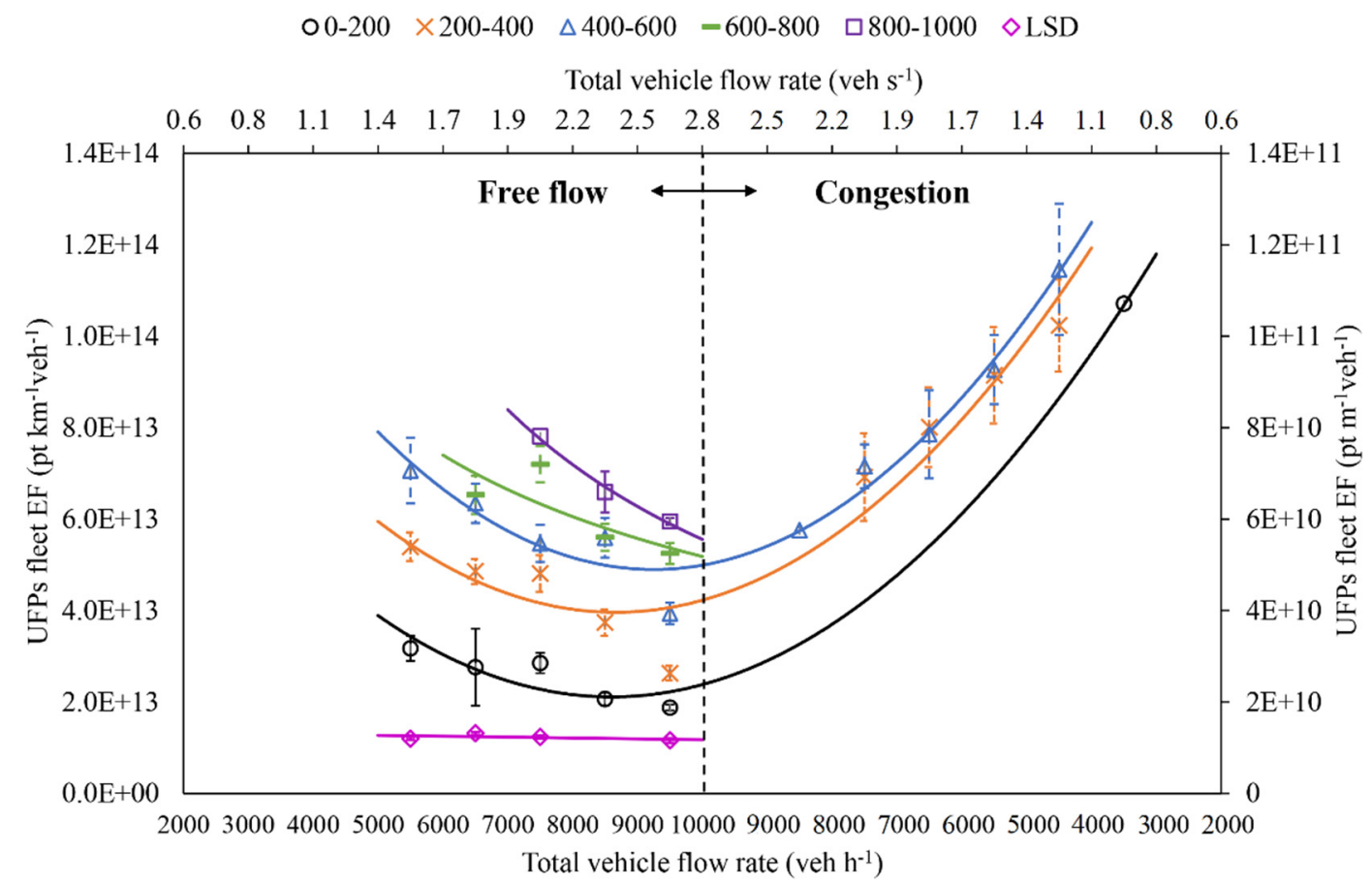

Fig. 6. Variation of UFP fleet emission factors calculated by Eq. (2) for free flow and congestion. The 5-min data were first divided into 1,000 veh $\mathrm{h}^{-1}$ intervals then categorized into different HDV flow rates. LSD data is modified from Xiang et al. 2019. Bars indicate one standard deviation.

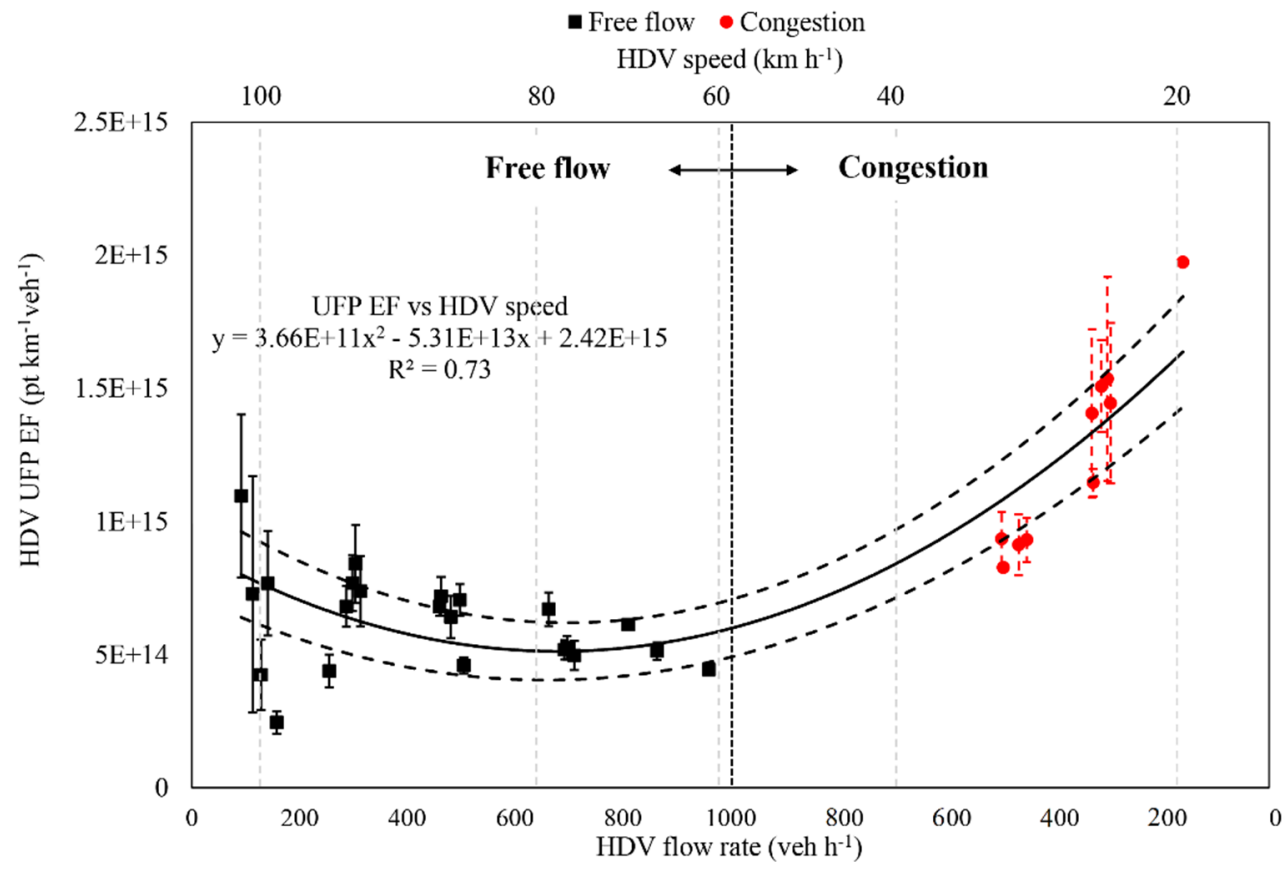

Fig. 7. Variations in HDV UFP emission factors with HDV flow rate and speed for different vehicle mode of operation (free flow and congestion) using Eq. (3). Bars indicate one standard deviation.

$7 \times 10^{14}$ to $30 \times 10^{14} \mathrm{pt} \mathrm{km}^{-1} \mathrm{veh}^{-1}$. For congestion conditions, the range was from $1 \times 10^{14}$ to $55 \times 10^{14} \mathrm{pt} \mathrm{km}^{-1} \mathrm{veh}^{-1}$. UFP EFs from this study are within the range of the average value reported from other studies (See Fig. 8). The wide range of reported UFP EFs reported in the literature indicates the need to evaluate addition information to address the differences in (vehicle operation, instrumentation, road type and sample site location).

When compared to the study that were conducted near a LDV-only roadway, the UFP EFs for HDVs not only show significant larger values but also present a different trend as a function of vehicle speed (Xiang et al., 2019, this issue). 
Table 2. Detail information reported in literatures and this study.

\begin{tabular}{|c|c|c|c|c|c|c|c|}
\hline \multirow{2}{*}{ Reference } & \multirow{2}{*}{$\begin{array}{l}\text { Size range } \\
(\mathrm{nm})\end{array}$} & \multirow{2}{*}{ Road type } & \multirow{2}{*}{$\begin{array}{l}\text { Vehicle flow } \\
\text { rate }\left(\text { veh day }{ }^{-1}\right)\end{array}$} & \multirow{2}{*}{$\begin{array}{l}\text { Vehicle mode } \\
\text { of operation }\end{array}$} & \multicolumn{2}{|c|}{ Vehicle speed $\left(\mathrm{km} \mathrm{h}^{-1}\right)$} & \multirow{2}{*}{$\begin{array}{l}\text { Instrument } \\
\text { location }\end{array}$} \\
\hline & & & & & LDV & $\mathrm{HDV}$ & \\
\hline $\begin{array}{l}\text { Imhof et al. } \\
\text { (2005) }\end{array}$ & $>7$ & $\begin{array}{l}\text { Two-lane one } \\
\text { direction urban road }\end{array}$ & $\begin{array}{l}22,000 \\
\mathrm{HDV} \%=6.1\end{array}$ & congestion & $<50$ & $<50$ & $\begin{array}{l}1.5 \mathrm{~m} \text { to } \\
\text { roadside }\end{array}$ \\
\hline $\begin{array}{l}\text { Morawsk et } \\
\text { al. (2005) }\end{array}$ & $15-700$ & $\begin{array}{l}\text { Two-lane each } \\
\text { direction freeway }\end{array}$ & $\begin{array}{l}\text { n.a. } \\
\text { HDV } \%=6\end{array}$ & free flow & 100 & 100 & Bridge \\
\hline $\begin{array}{l}\text { Birmili et al. } \\
\text { (2009) }\end{array}$ & $10-500$ & $\begin{array}{l}\text { Three-lane each } \\
\text { direction urban road }\end{array}$ & $\begin{array}{l}180,000 \\
\mathrm{HDV} \%=6\end{array}$ & free flow & $75-90$ & $75-90$ & $\begin{array}{l}\text { Near roadside } \\
6 \mathrm{~m} \text { in height }\end{array}$ \\
\hline $\begin{array}{l}\text { Wang et al. } \\
\text { (2010) }\end{array}$ & $10-700$ & $\begin{array}{l}\text { Three-lane each } \\
\text { direction freeway }\end{array}$ & $\begin{array}{l}55,600 \\
\mathrm{HDV} \%=8\end{array}$ & free flow & 110 & 90 & $\begin{array}{l}3 \mathrm{~m} \text { to roadside } \\
3.1 \mathrm{~m} \text { in height }\end{array}$ \\
\hline $\begin{array}{l}\text { Nickel et al. } \\
(2013)\end{array}$ & $14-750$ & $\begin{array}{l}\text { Two-directional } \\
\text { freeway }\end{array}$ & $\begin{array}{l}79,500 \\
\mathrm{HDV} \%=18\end{array}$ & free flow & 120 & 80 & $\begin{array}{l}3 \text { or } 13 \mathrm{~m} \text { to } \\
\text { roadside }\end{array}$ \\
\hline $\begin{array}{l}\text { Krecl et al. } \\
\text { (2017) }\end{array}$ & $>28$ & $\begin{array}{l}\text { Two-lane each } \\
\text { direction urban road }\end{array}$ & n.a. & congestion & $<50$ & $<50$ & n.a \\
\hline $\begin{array}{l}\text { Krecl et al. } \\
(2018)\end{array}$ & $>10$ & $\begin{array}{l}\text { Two-lane one } \\
\text { direction urban road }\end{array}$ & $\begin{array}{l}10,150 \\
\mathrm{HDV} \%=34\end{array}$ & congestion & $<50$ & $<50$ & $7 \mathrm{~m}$ in height \\
\hline This work & $20-1000$ & $\begin{array}{l}\text { Seven-lane one } \\
\text { direction freeway }\end{array}$ & $\begin{array}{l}150,000 \\
\mathrm{HDV} \%=8.4\end{array}$ & $\begin{array}{l}\text { free } \\
\text { flow/congestion }\end{array}$ & $10-130$ & $9-110$ & $\begin{array}{l}3 \mathrm{~m} \text { to roadside } \\
4 \mathrm{~m} \text { in height } \\
\end{array}$ \\
\hline
\end{tabular}

(a)

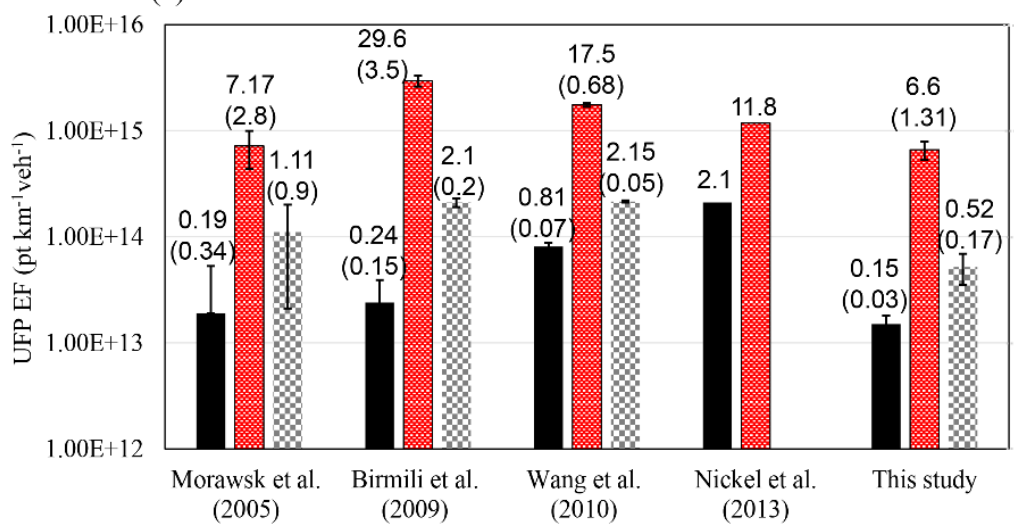

(b)

- LDV 圈HDV Fleet mixed

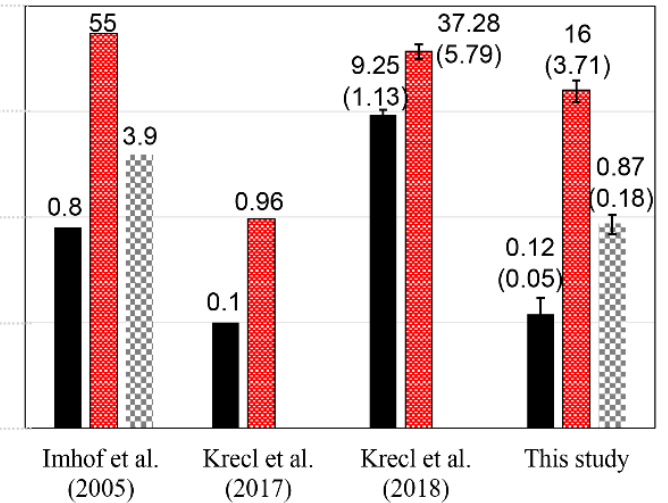

Fig. 8. Comparison of this study and literature reported average UFP EFs for (a) free flow and (b) congestion conditions.

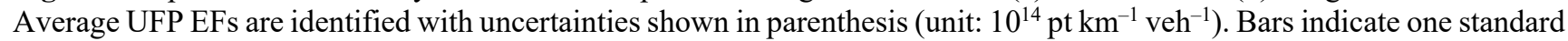
deviation.

This can be caused by different operating mechanism in gasoline and diesel engines and distinct driving cycles and this requires that need more real-world and laboratory investigations.

\section{ACKNOWLEDGMENTS}

We would like to thank all participants in the field measurement, in particular Liuyang Sun, Xuexuan Peng for collecting field samples.

\section{DISCLAIMER}

Reference to any companies or specific commercial products does not constitute endorsement.

\section{REFERENCES}

Abu-Allaban, M., Coulomb, W., Gertler, A., Gillies, J.,
Pierson, W., Rogers, C., Sagebiel, J. and Tarnay, L. (2002). Exhaust particle size distribution measurements at the tuscarora mountain tunnel. Aerosol Sci. Technol. 36: 771-789.

Alonso-Estébanez, A., Pascual-Muñoz, P., Yagüe, C., Laina, R. and Castro-Fresno, D. (2012). Field experimental study of traffic-induced turbulence on highways. Atmos. Environ. 61: 189-196.

Arya, S.P. (1999). Air pollution meteorology and dispersion. Oxford University Press New York.

Benson, P.E. (1984). CALINE4 - A dispersion model for predicting air pollutant concentrations near roadways. California Department of Transportation, Office of Transportation Laboratory, California.

Berkowicz, R., Hertel, O., Larsen, S., Sørensen, N. and Nielsen, M. (1997). Modelling traffic pollution in streets. National Environmental Research Institute, Roskilde, Denmark 10129: 20.

Bhautmage, U. and Gokhale, S. (2016). Effects of moving- 
vehicle wakes on pollutant dispersion inside a highway road tunnel. Environ. Pollut. 218: 783-793.

Birmili, W., Alaviippola, B., Hinneburg, D., Knoth, O., Tuch, T., Borken-Kleefeld, J. and Schacht, A. (2009). Dispersion of traffic-related exhaust particles near the Berlin urban motorway - Estimation of fleet emission factors. Atmos. Chem. Phys. 9: 2355-2374.

Carpentieri, M., Kumar, P. and Robins, A. (2012). Wind tunnel measurements for dispersion modelling of vehicle wakes. Atmos. Environ. 62: 9-25.

Chock, D.P. (1980). General motors sulfate dispersion experiment. Boundary Layer Meteorol.. 18: 431-451.

Eskridge, R.E. and Hunt, J. (1979). Highway Modeling. Part I: Prediction of velocity and turbulence fields in the wakes of vehicles. J. Appl. Meteorol. 18: 387-400.

Eskridge, R.E. and Thompson, R.S. (1982). Experimental and theoretical study of the wake of a block-shaped vehicle in a shear-free boundary flow. Atmos. Environ. 16: 2821-2836.

Gordon, M., Staebler, R.M., Liggio, J., Makar, P., Li, S.M., Wentzell, J., Lu, G., Lee, P. and Brook, J.R. (2012). Measurements of enhanced turbulent mixing near highways. J. Appl. Meteoeol. Clim. 51: 1618-1632.

Grønskei, K. (1988). The influence of car speed on dispersion of exhaust gases. Atmos. Environ. 22: 273-281.

Hietikko, R., Kuuluvainen, H., Harrison, R.M., Portin, H., Timonen, H., Niemi, J.V. and Rönkkö, T. (2018). Diurnal variation of nanocluster aerosol concentrations and emission factors in a street canyon. Atmos. Environ. 189: 98-106.

Huang, L., Gong, S., Gordon, M., Liggio, J., Staebler, R., Stroud, C., Lu, G., Mihele, C., Brook, J. and Jia, C. (2014). Aerosol-computational fluid dynamics modeling of ultrafine and black carbon particle emission, dilution, and growth near roadways. Atmos. Chem. Phys. 14: 12631-12648.

Imhof, D., Weingartner, E., Ordóñez, C., Gehrig, R., Hill, M., Buchmann, B. and Baltensperger, U. (2005). Realworld emission factors of fine and ultrafine aerosol particles for different traffic situations in Switzerland. Environ. Sci. Technol. 39: 8341-8350.

Jones, A.M. and Harrison, R.M. (2006). Estimation of the emission factors of particle number and mass fractions from traffic at a site where mean vehicle speeds vary over short distances. Atmos. Environ. 40: 7125-7137.

Kalthoff, N., Bäumer, D., Corsmeier, U., Kohler, M. and Vogel, B. (2005). Vehicle-induced turbulence near a motorway. Atmos. Environ. 39: 5737-5749.

Kastner-Klein, P., Berkowicz, R. and Plate, E. (2000). Modelling of vehicle-induced turbulence in air pollution studies for streets. Int. J. Environ. Pollut. 14: 496-507.

Kim, Y., Huang, L., Gong, S. and Jia, C.Q. (2016). A New approach to quantifying vehicle induced turbulence for complex traffic scenarios. Chin. J. Chem. Eng. 24: 71-78.

Krecl, P., Johansson, C., Targino, A.C., Ström, J. and Burman, L. (2017). Trends in black carbon and sizeresolved particle number concentrations and vehicle emission factors under real-world conditions. Atmos. Environ. 165: 155-168.
Krecl, P., Targino, A.C., Landi, T.P. and Ketzel, M. (2018). Determination of black carbon, $\mathrm{PM}_{2.5}$, particle number and $\mathrm{NO}_{\mathrm{x}}$ emission factors from roadside measurements and their implications for emission inventory development. Atmos. Environ. 186: 229-240.

Kurniawan, A. and Schmidt-Ott, A. (2006). Monitoring the soot emissions of passing cars. Environ. Sci. Technol. 40: 1911-1915.

Lo, K.H. and Kontis, K. (2017). Flow around an articulated lorry model. Exp. Therm Fluid Sci. 82: 58-74.

Mannering, F.L. and Washburn, S.S. (2012). Principles of highway engineering and traffic analysis. Wiley.

McArthur, D., Burton, D., Thompson, M. and Sheridan, J. (2016). On the near wake of a simplified heavy vehicle. J. Fluids Struct. 66: 293-314.

Miller, S.J., Gordon, M., Staebler, R.M. and Taylor, P.A. (2019). A study of the spatial variation of vehicle-induced turbulence on highways using measurements from a mobile platform. Boundary Layer Meteorol. 171: 1-29.

Morawska, L., Jamriska, M., Thomas, S., Ferreira, L., Mengersen, K., Wraith, D. and McGregor, F. (2005). Quantification of particle number emission factors for motor vehicles from on-road measurements. Environ. Sci. Technol. 39: 9130-9139.

Nickel, C., Kaminski, H., Hellack, B., Quass, U., John, A., Klemm, O. and Kuhlbusch, T.A. (2013). Size resolved particle number emission factors of motorway traffic differentiated between heavy and light duty vehicles. Aerosol Air Qual. Res. 13: 450-461.

Ntziachristos, L., Ning, Z., Geller, M.D. and Sioutas, C. (2007). Particle concentration and characteristics near a major freeway with heavy-duty diesel traffic. Environ. Sci. Technol. 41: 2223-2230.

Palmgren, F., Berkowicz, R., Ziv, A. and Hertel, O. (1999). Actual car fleet emissions estimated from urban air quality measurements and street pollution models. Sci. Total Environ. 235: 101-109.

Pavageau, M. and Schatzmann, M. (1999). Wind tunnel measurements of concentration fluctuations in an urban street canyon. Atmos. Environ. 33: 3961-3971.

Rao, K., Gunter, R., White, J. and Hosker, R. (2002). Turbulence and dispersion modeling near highways. Atmos. Environ. 36: 4337-4346.

Rönkkö, T., Kuuluvainen, H., Karjalainen, P., Keskinen, J., Hillamo, R., Niemi, J.V., Pirjola, L., Timonen, H.J., Saarikoski, S. and Saukko, E. (2017). Traffic Is a major source of atmospheric nanocluster aerosol. Proc. Natl. Acad. Sci. U.S.A. 114: 7549-7554.

Sahlodin, A.M., Sotudeh-Gharebagh, R. and Zhu, Y. (2007). Modeling of dispersion near roadways based on the vehicle-induced turbulence concept. Atmos. Environ. 41: 92-102.

Seinfeld, J.H. and Pandis, S.N. (2016). Atmospheric chemistry and physics: From air pollution to climate change. John Wiley \& Sons.

Tong, Z., Whitlow, T.H., MacRae, P.F., Landers, A.J. and Harada, Y. (2015). Quantifying the effect of vegetation on near-road air quality using brief campaigns. Environ. Pollut. 201: 141-149. 
Trivikrama Rao, S., Sedefian, L. and Czapski, U.H. (1979). Characteristics of turbulence and dispersion of pollutants near major highways. J. Appl. Meteoeol. 18: 283-293.

U.S. Environmental Protection Agency (U.S. EPA) (2014). Motor Vehicle Emission Simulator (MOVES): User Guide for MOVES2014. Report EPA-420-B-14-055; Assessment and Standards Division, Office of Transportation and Air Quality, U.S. Environmental Protection Agency, Washington, DC. https://nepis.epa.gov/Exe/ZyPDF.cgi? Dockey=P100JWAL.pdf.

Wang, F., Ketzel, M., Ellermann, T., Wåhlin, P., Jensen, S.S., Fang, D. and Massling, A. (2010). Particle number, particle mass and $\mathrm{NO}_{\mathrm{x}}$ emission factors at a highway and an urban street in Copenhagen. Atmos. Chem. Phys. 10: 2745-2764.

Wang, Y.J. and Zhang, K.M. (2012). Coupled Turbulence and aerosol dynamics modeling of vehicle exhaust plumes using the ctag model. Atmos. Environ. 59: 284 293.

Wang, Y.J., Nguyen, M.T., Steffens, J.T., Tong, Z., Wang, Y., Hopke, P.K. and Zhang, K.M. (2013). Modeling multi-scale aerosol dynamics and micro-environmental air quality near a large highway intersection using the ctag model. Sci. Total Environ. 443: 375-386.

Wang, Z.S., Chien, C.J. and Tonnesen, G.S. (2009). Development of a tagged species source apportionment algorithm to characterize three-dimensional transport and transformation of precursors and secondary pollutants. $J$. Geophys. Res. 114: D21206.

Xiang, S., Hu, Z., Zhai, W., Wen, D. and Noll, K.E. (2018). Concentration of ultrafine particles near roadways in an urban area in Chicago, Illinois. Aerosol Air Qual. Res. 18: 895-903.

Xiang, S., Yu, Y., Hu, Z. and Noll, K. (2019). Characterization of dispersion and ultrafine-particle emission factors based on near-roadway monitoring Part I: Light duty vehicles. Aerosol Air Qual. Res., in Press.

Zhang, K., Batterman, S. and Dion, F. (2011). Vehicle emissions in congestion: Comparison of work zone, rush hour and free-flow conditions. Atmos. Environ. 45: 19291939.

Zhang, K.M. and Wexler, A.S. (2002). Modeling the number distributions of urban and regional aerosols: Theoretical foundations. Atmos. Environ. 36: 1863-1874.

Zhang, K.M. and Wexler, A.S. (2004). Evolution of particle number distribution near roadways-Part I: Analysis of aerosol dynamics and its implications for engine emission measurement. Atmos. Environ. 38: 6643-6653.

Zhang, K.M., Wexler, A.S., Zhu, Y.F., Hinds, W.C. and Sioutas, C. (2004). volution of particle number distribution near roadways. Part II: The 'Road-to-Ambient' process. Atmos. Environ. 38: 6655-6665.

Zhang, K.M., Wexler, A.S., Niemeier, D.A., Zhu, Y.F., Hinds, W.C. and Sioutas, C. (2005). Evolution of particle number distribution near roadways. Part III: Traffic analysis and on-road size resolved particulate emission factors. Atmos. Environ. 39: 4155-4166.

Received for review, August 9, 2019

Revised, October 16, 2019

Accepted, October 19, 2019 